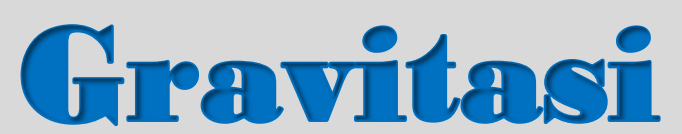

\title{
Identifikasi Lapisan Akuifer Dengan Metode Geolistrik di Kelurahan Poboya Kota Palu
}

\author{
(Identification of the Aquifer Layer by Geoelectric Method in Poboya Sub-district Palu City)
}

\author{
Riskawati dan Abdullah \\ Jurusan Fisika Fakultas Matematika dan Ilmu Pengetahuan Alam Universitas Tadulako
}

\section{Info}

\section{Article history:}

Received: 14 July 2021

Accepted: 30 December 2021

Published: 31 December 2021

\begin{abstract}
Abstrak.
Telah dilakukan penelitian dengan judul "Identifikasi Lapisan Akuifer di Kelurahan Petobo Kota Palu Menggunakan Metode Geolistrik Hambatan Jenis" bertujuan untuk mengetahui keberadaan serta kedalaman lapisan akuifer setelah likuefaksi. Penelitian ini menggunakan metode Automatic Array Scanning (AAS) dengan konfigurasi dipole-dipole serta diolah menggunakan Software Earthimager 2D dan Surfer 11. Hasil yang diperoleh menunjukkan lapisan dengan nilai hambatan jenis yang berkisar antara 30,92-77,3 $\Omega \mathrm{m}$ dengan nilai faktor formasi $2-5$, diduga merupakan lapisan akuifer yang terdiri atas pasir dan kerikil ditunjukkan dengan warna hijau kekuningkuningan hingga warna kuning. Lapisan ini berada pada kedalaman $4 \mathrm{~m}$ hingga $38 \mathrm{~m}$ di bawah permukaan tanah dengan ketebalan berkisar 16-46 m. Lapisan akuifer mendangkal dan semakin menebal ke arah barat.
\end{abstract}

\section{Abstract.}

This research has been done with title "Identification of aquifer layer in Petobo village, Palu City, using Geoelectric Resistivity Method" aims to know the existence and depth of the layer of aquifer in Petobo village, Palu city after the liquefaction. The research uses Automatic Array Scanning $(A A S)$ method with dipole-dipole configuration and processed using Earthimager2D Software and Surfer 11. The results show a layer with the value of resistivity ranges between 30,92-77,3 $\Omega \mathrm{m}$ with a formation factor value of 2-5, allegedly a layer of aquifer consisting of sand and gravel shown in a yellowish green to yellow. This layer is at a depth of $4 \mathrm{~m}$ to $38 \mathrm{~m}$ below the ground surface with thicknesses ranging from 16-46 m. Aquifer layer is shallow and thickening towards the west.

\author{
Kata kunci: \\ Akuifer \\ Konfigurasi Schlumberger \\ Resistivitas \\ Keywords: \\ Aquifer \\ Geoelectric \\ Schlumberger configuration \\ Resistivity
}

*) e-mail: watiriska988@gmail.com

DOI: $10.22487 /$ gravitasi.v20i2.15737

\section{PENDAHULUAN}

Air adalah sumber daya alam yang mutlak dibutuhkan oleh setiap makhluk hidup dimuka bumi. Laju pertumbuhan penduduk dan pemukiman yang semakin padat tentu seiring pemakaian air akan semakin meningkat. Oleh karena itu sebaiknya dalam upaya eksplorasi air diperlukan adanya penafsiran, perencanaan dan pengembangan yang tepat, pemakaian air harus hemat dan terus berupaya melindungi kelestarian sumber daya alam ini.

Kelurahan Poboya Kecamatan Mantikulore Kota Palu Provinsi Sulawesi Tengah Indonesia merupakan daerah yang sangat sulit mengakses air bersih. Sungai Poboya merupakan sumber air yang cukup melimpah, namun masyarakat di Poboya malah sulit mengakses air bersih. Adapun sumber air yang digunakan oleh warga ada 3 macam kategori yang pertama menggunakan air PDAM, sumur bor dan ada juga yang membeli dengan harga Rp.75.000/tangki.

Identifikasi akuifer yang memadai perlu dilakukan survei lapangan secara mendetail agar memberikan informasi yang dibutuhkan dalam upaya eksplorasi nantinya. Misalnya dalam proses pembuatan sumur bor dibutuhkan informasi lapisan batuan bawah permukaan untuk mengetahui anggaran yang bisa dirancang sesuai kebutuhan ketika proses pengeboran. karena dari informasi ini didapatkan tebal dan ketebalan lapisan akuifer berdasarkan nilai resistivitas material bawah tanahnya. Kegiatan identifikasi ini dilaksanakan di Kelurahan Poboya dengan metode pengukuran geofisika yang efektif digunakan yaitu metode geolistrik (resistivitas) sounding konfigurasi schlumberger [1]. 
Salah satu sumber air bagi kehidupan makhluk hidup di muka bumi adalah airtanah. Sejak jaman kuno telah dilakukan usaha memanfaatkan dan mengembangkan air tanah biasanya menggunakan ember yang ujungnya diikat pada bambu kemudian dilengkapi dengan sistem pegas atau pemberat. Dengan perkembangan teknologi pengeboran sumur-sumur dalam sampai kedalaman 200 meter. Agar bisa diketahui ada atau tidaknya lapisan pembawa air (akuifer), ketebalan dan kedalamannya serta untuk mengambil contoh air untuk dianalisis kualitas airnya maka usaha untuk mendapatkan susunan mengenai lapisan bumi, kegiatan penyelidikan melalui permukaan tanah atau bawah tanah haruslah dilakukan,. Penyelidikan permukaan tanah merupakan awal penyelidikan yang cukup penting paling tidak dapat memberikan suatu gambaran mengenai lokasi keberadaan air tanah tersebut meskipun airtanah tidak dapat secara langsung diamati melalui permukaan bumi [2].

Airtanah merupakan salah satu komponen dalam daur hidrologi yang berlangsung di alam. Sumber air ini terbentuk dari air hujan yang meresap ke dalam tanah dan merembes melalui lapisan batuan, terutama lapisan pembawa air dalam satu cekungan airtanah yang berada di bawah permukaan menuju ke daerah lepasan. Kondisi lingkungan, seperti iklim, geologi, dan vegetasi sangat erat kaitannya dengan proses ini dapat dipahami bahwa keterdapatan air tanah [3]. Airtanah bukan mineral atau bahan tambang yang terpakai habis namun merupakan bahan cair yang dapat diperbaharui. Selama tidak terjadi perubahan iklim, bahan cair ini secara terus menerus diperbaharui. Airtanah yang tersedia akan tetap ada karena selalu terjadi pengisian kembali pada waktu musim hujan. Keadaan morfologi, hidrologi dan keadaan geologi setempat dapat mempengaruhi airtanah dalam bergerak secara leteral maupun vertikal. Bentuk dan penyebaran besar butiran, perbedaan dan penyebaran lapisan batuan dan struktur geologi adalah faktor geologi yang berpengaruh dalam gerakan tersebut. Sedangkan pengaruh hidrologi terhadap airtanah adalah kuantitas prespitasi, daya infiltrasi serta banyaknya penguapan dan pengaruh iklim, sehingga dapat disimpulkan banyaknya kandungan airtanah disuatu daerah tergantung pada [4]:

1. Iklim/musim atau banyaknya curah hujan

2. Banyak sedikitnya tumbuh-tumbuhan misalnya hutan

3. Topografi, misalnya lereng, datar

4. Derajat keserangan/derajat celah batuan.

Lapisan bawah permukaan yang dapat menyimpan dan mengalirkan air disebut sebagai lapisan akuifer. Lapisan ini merupakan formasi geologi yang mengandung air dan memindahkannya dari satu titik ke titik yang lain dalam jumlah yang mencukupi untuk pengembangan ekonomi. Lapisan ini dapat dikatakan lapisan permeabel atau lapisan pembawa air [5].

Dalam bidang hidrogeologi, formasi batuan/ yang mempunyai kemampuan menyimpan dan mengalirkan airtanah dengan jumlah yang berarti (significant) merupakan akuifer. Ruang antar butiran pada batuan-batuan yang berumur tua menjadi rapat, menyebabkan tidak bisa menampung dan meloloskan air dalam jumlah banyak dan bahkan menjadi kedap air (impermeable). Sama halnya dengan batuan beku dan batuan metamorfik yang memiliki permeabilitas dan porositasnya kecil. Pada zona-zona seperti ini sangat sulit sekali diharapkannya ada airtanah kecuali batuan-batuan tersebut banyak mengandung rekahan yang disebut akuifer rekahan (fracture akuifer). Ada 3 kemungkinan penyebab rekahan, yaitu:

1. Efek struktur regional (flexing and faulting).

2. Erosi batuan dan pelepasan tekanan dari overburden.

3. Pendinginan yang berlangsung pada saat pembentukan batuan.

Berdasarkan litologinya akuifer dapat dibedakan menjadi beberapa macam yaitu sebagai berikut [6]:

1. Akuifer bebas (unconfined aquifer), adalah lapisan lolos air yang hanya sebagian terisi oleh air dan berada diatas lapisan kedap air. Permukaan tanah pada akuifer ini disebut dengan watertable, yaitu permukaan air yang mempunyai tekanan hidrostatik sama dengan atmosfer.

2. Akuifer setengah bebas (semi unconfined aquifer), merupakan peralihan antara akuifer setengah tertekan dengan akuifer bebas. Lapisan bawahnya yang merupakan lapisan kedap air, sedangkan lapisan atasnya merupakan material berbutir halus, sehingga pada lapisan penutupnya masih dimungkinkan adanya gerakan air.

3. Akuifer setengah tertekan (semi confined aquifer), adalah akuifer yang lapisan di atas atau di bawahnya masih mampu meloloskan atau dilewati air meskipun sangat kecil (lambat).

4. Akuifer tertekan (confined aquifer), adalah akuifer yang lapisan atas dan bawahnya dibatasi oleh lapisan yang kedap air.

Batuan merupakan suatu jenis materi sehingga juga memiliki sifat-sifat kelistrikan. Jika arus listrik dialirkan ke dalam batuan maka memberikan respon yang sesuai sifat listrik batuan tersebut. Menurut Taib (1990), aliran (konduksi) arus listrik di dalam batuan/mineral digolongkan menjadi 3 macam, yaitu konduksi elektronik, konduksi elektrolitik, dan konduksi dielektrik [7]. Konduksi elektronik terjadi jika batuan/mineral mempunyai banyak elektron bebas sehingga arus listrik dialirkan dalam batuan/mineral oleh elektron bebas, Konduksi elektrolitik terjadi jika batuan/mineral bersifat porus dan pori-pori nya terisi cairan elektrotitik. Pada kondisi ini arus listrik dibawa oleh ion-ion elektrolit. Konduksi dielektrik terjadi jika terjadi polarisasi muatan saat bahan dialiri listrik.

Berdasarkan harga resistivitas listriknya, batuan/ mineral digolongkan menjadi 3 yaitu:
a. Konduktor baik
$: 10^{-6}<\rho<1(\Omega \mathrm{m})$
b. Konduktor buruk
$: 1<\rho<10^{7}(\Omega \mathrm{m})$
c. Isolator
: $\rho>10^{7}(\Omega \mathrm{m})$

Hubungan antara resistivitas dengan porositas pertama kali diusulkan oleh Archie. Hubungan resistivitas $(\rho)$ dan porositas ( $\phi)$ dinyatakan dalam Persamaan Archie (persamaan 2.1):

$\rho=a \rho_{w} \emptyset^{-m}$

Sedangkan untuk porositas batuan yang porinya tidak terisi air, dinyatakan dalam Persamaan 2.2 Archie:

$\rho t=\rho_{b} S_{w}^{-m}=a \rho_{w} \emptyset^{-m} S_{w}^{-m}$

Hubungan resistivitas dalam Persamaan 2.2 dysreflexia dengan besar faktor formasi $(\mathrm{F})$, yaitu:

$F=\frac{\rho}{\rho_{w}}=\frac{a}{\phi^{m}}$ 
Faktor formasi merupakan besaran tersebut berefleksi sebagai porositas pada batuan sedimen maupun batuan beku yang mengalami rekahan sehingga dapat digunakan untuk pendugaan zona akuifer. Pengukuran resistivitas $\rho$ dapat dilakukan langsung di lapangan pada suatu eksplorasi hidrogeologi, misalnya dengan menggunakan metode hambatan jenis. Resistivitas air pengisi berpori $\rho_{w}$ selain dapat diukur secara langsung juga dapat dihitung dengan menggunakan persamaan:

$\rho_{w}=10000 / \mathrm{DHL}$

dimana DHL adalah daya hantar listrik yang dinyatakan dalam $(\mu S)$. Dari kedua besaran tersebut dapat dihitung nilai faktor formasi (F) dengan menggunakan Persamaan 2.3. Beberapa kesimpulan nilai faktor formasi dari beberapa studi hidrogeologi yang diperoleh seperi pada Tabel 1 .

Tabel 1 Klasifikasi pendugaan faktor formasi untuk batuan sedimen

\begin{tabular}{|c|c|c|}
\hline $\mathbf{F}$ & Formasi & Akuifer/Akuiklud \\
\hline$\leq 1$ & Lempung & Akuiklud \\
\hline $1-1,5$ & $\begin{array}{c}\text { Gambut, pasir } \\
\text { tanah liat atau lanau }\end{array}$ & Akuiklud \\
\hline 2 & Lanau - pasir temuan & $\begin{array}{c}\text { Akuifer sedikit sampai } \\
\text { sedang }\end{array}$ \\
\hline 3 & Pasir sedang & $\begin{array}{l}\text { Akuifer sedang sampai } \\
\text { produktif }\end{array}$ \\
\hline 4 & Pasir kasar & Akuifer produktif \\
\hline 5 & Kerikil & $\begin{array}{c}\text { Akuifer sangat } \\
\text { produktif }\end{array}$ \\
\hline
\end{tabular}

(Sumber: Taib [7])

Nilai ketebalan dan tahanan jenis batuan di bawah permukaan dapat diketahui dengan menggunakan metode geolistrik terdiri dari beberapa konfigurasi. Metode geolistrik konfigurasi Schlumberger merupakan metode yang banyak digunakan untuk mengetahui karakteristik lapisan batuan bawah permukaan khususnya untuk mencari keberadaan lapisan akuifer. Metode ini berbia biaya survei yang relatif murah, namun mampu untuk mendeteksi adanya non homogenitas lapisan batuan bawah permukaan. Umumnya sifat homogen sempurna tidak terjadi pada lapisan batuan. Hasil pengukuran sangat dipengaruhi posisi lapisan batuan yang terletak dekat dengan permukaan. Nilai yang terukur adalah tahanan jenis semu [8].

Menurut Loke (2000), dalam teknik ini pengukurannya adalah pengaturan elektroda dilakukan dengan jarak spasi elektroda diubah-ubah secara gradual untuk titik yang diamati, sedangkan elektroda potensial (M dan N) dibuat tetap [9]. Arus Listrik yang diinjeksikan semakin dalam jika semakin besar jarak elektroda hingga semua lokasi pengukuran terlingkupi. Dimana hambatan jenisnya diberikan oleh Persamaan:

$\rho=\frac{\pi\left(L^{2}-l^{2}\right)}{2 l} \frac{\Delta V}{\mathrm{I}}=K \frac{\Delta V}{\mathrm{I}}$

Pada penelitian ini konfigurasi yang digunakan adalah konfigurasi Schlumberger yang menggunakan 2 elektroda arus dan 2 elektroda potensial dengan skema pada Gambar 1. A dan $\mathrm{B}$ merupakan elektroda arus, sedangkan $\mathrm{M}$ dan $\mathrm{N}$ adalah elektroda potensial. Dari Gambar 1 faktor geometri dari konfigurasi ini dipengaruhi oleh jarak $\mathrm{AB}$ dan $\mathrm{MN}$ dengan persamaan sebagai berikut [9].

$K=\frac{\pi\left(L^{2}-l^{2}\right)}{2 l}$

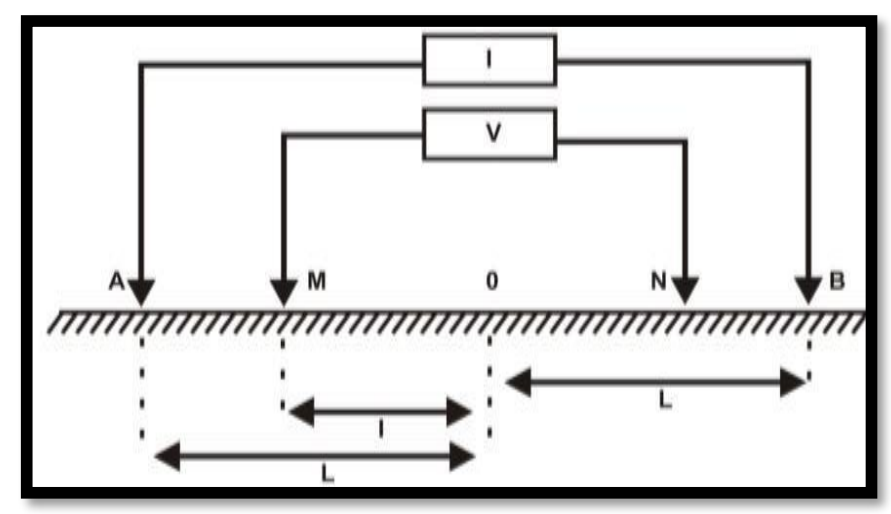

Gambar 1 Skema elektroda geolistrik konfigurasi Schlumberger [9]

\section{BAHAN DAN METODE}

Lokasi penelitian dilakukan di Kelurahan Poboya Kecamatan Mantikulore Kota Palu Sulawesi Tengah Indonesia. Secara geografis lokasi penelitian terletak pada Posisi 119 $54^{\prime} 26^{\prime \prime}$ BT sampai dengan $119^{\circ} 54^{\prime} 23^{\prime \prime}$ BT dan 0 $053^{\prime} 1^{\prime \prime}$ LS sampai dengan 0 53'3" LS. Untuk melihat secara jelas kondisi lokasi penelitian, ditampilkan peta lokasi penelitian pada Gambar 2.

Peralatan yang digunakan pada penelitian ini yaitu:

1. Satu set alat ukur terdiri dari:
a. Resistivitimeter,
b. Elektroda 4 buah
c. Kabel 4 buah,
d. Sumber arus listrik (accu),
e. Kabel penghubung

2. Meteran

3. Global Positiong System (GPS),

4. Kompas geologi

5. Konduktivitimeter

6. Palu

7. Peta Geologi Lembar Palu Sulawesi tengah skala $1: 250.000$.

8. Alat tulis

9. Laptop

Proses pengambilan data di lapangan dilakukan pada 4 titik pengukuran dengan langkah-langkah berikut:

1. Menentukan posisi titik-titik pengukuran dan mengupayakan agar setiap titik ukur membentuk garis lurus agar dapat dikorelasikan satu sama lain.

2. Menentukan arah bentangan menggunakan kompas dan pengukuran koordinat geografis serta ketinggiannya dari permukaan laut menggunakan GPS.

3. Merangkai alat resistivitimeter

4. Membentangkan meteran untuk menentukan titik elektroda potensial, diawali dengan (MN/2) pada jarak 0,5 $m$ dan elektroda arus (AB/2) pada jarak bentangan 1,5-15 $\mathrm{m}$ kemudian menyambungkan elektroda dan resistivitimeter dengan menggunakan kabel.

5. Menginjeksi arus ke dalam tanah melalui elektroda arus dan mengukur kuat arus (I) dan beda potensial (V).

6. Selanjutnya memperbesar bentangan $(\mathrm{AB} / 2=15-75 \mathrm{~m})$, $(\mathrm{MN} / 2=5 \mathrm{~m})$ dan $(\mathrm{AB} / 2=75-200 \mathrm{~m}),(\mathrm{MN} / 2=25 \mathrm{~m})$ 
dengan waktu pengambilan data di lapangan $\pm 1-2$ jam. Data yang diperoleh dari pengukuran adalah nilai beda potensial (V), dan kuat arus (I), jarak elektroda (AB/2 dan $\mathrm{MN} / 2$ ) serta nilai faktor geometri (K). Dengan menggunakan persamaan (2.8) maka diperoleh nilai hambatan jenis semu $\left(\rho_{a}\right)$ hasil pengukuran.

7. Pengukuran selanjutnya adalah dengan memperbesar jarak $\mathrm{AB} / 2$.

8. Melakukan pengambilan data kembali berdasarkan prosedur 3 sampai 7.

9. Mengambil sampel air dari beberapa sumur warga.

Pengolahan data dilakukan dengan langkah langkah sebagai berikut:

1. Menghitung hambatan jenis semu $\left(\rho_{a}\right)$ menggunakan persamaan (2.8)

2. Memplot data nilai hambatan jenis pada kertas bilog.

3. Mengolah data hasil pengukuran beda potensial (V), arus (I), hambatan jenis semu $\left(\rho_{a}\right)$ dan faktor geometri menggunakan Ipi2win.

4. Kemudian mengolah data hasil pengukuran menggunakan software progress dengan penginputan hasil data dari software Ipi2win.

5. Mengukur parameter daya hantar listrik (DHL) dengan menggunakan Xplore GLX.

6. Kemudian hasil inversi keseluruhan titik duga dikorelasikan satu sama lain, dengan mempertimbangkan kondisi geologi, morfologi dan DHL maka nilai hambatan jenis yang diperoleh diinterpretasi.

7. Hasil interpretasi digambarkan dalam bentuk penampang 2D dengan menggunkan program Coreldraw.

Dari hasil pengolahan data menggunakan software Ipi2win diperoleh nilai hambatan jenis dan kedalaman, penentuan akuifer akan dihubungkan dari nilai resistivitas. Setiap pengukuran kemudian dianalisa dan diinterpretasikan. Tahapan interpretasi adalah penafsiran data hasil pengolahan data untuk mendapatkan kondisi kedalaman dan nilai resistivitas ril dari daerah penelitian yang selanjutnya dilakukan penafsiran kondisi bawah permukaan untuk mengetahui lapisan akuifer. Untuk memperoleh hasil interpretasi yang lebih akurat, maka diperlukan data-data pendukung yang berhubungan dengan kondisi daerah penelitian. Data-data yang diperlukan diantaranya, peta geologi, peta rupa bumi dan data daya hantar listrik (DHL) air.

\section{HASIL DAN PEMBAHASAN}

Dasar menginterpretasi hasil pengolahan data di daerah penelitian adalah nilai hambatan jenis setiap titik pengukuran, data DHL, dan kondisi geologi. Kondisi geologi daerah penelitian berada pada formasi molasa celebes sarasin dan sarasin, aluvium dan endapan pantai, maka digunakan klasifikasi pendugaan lapisan akuifer faktor formasi batuan sedimen (Tabel 1). Untuk menginterpretasi lapisan dan sebaran akuifer di lokasi penelitian, maka setiap titik pengukuran dikorelasikan dalam beberapa penampang hambatan jenis. Korelasi tersebut dapat dilihat pada Gambar 3 dan Gambar 4.

Penampang hambatan jenis model A-C pada Gambar 3 menunjukkan korelasi antara 3 titik pengukuran yaitu $\mathrm{L}_{1}, \mathrm{~L}_{2}$, dan $\mathrm{L}_{3}$. Jarak $\mathrm{L}_{1}$ ke $\mathrm{L}_{2}$ yang terukur sebesar $336 \mathrm{~m}$ dan jarak $\mathrm{L}_{2}$ ke $\mathrm{L}_{3}$ yang terukur sebesar $335 \mathrm{~m}$ sehingga jarak keseluruhan penampang A-C sebesar $671 \mathrm{~m}$ dengan ketinggian yang terukur 130-153 mdpl. Di penampang ini setiap titik pengu-

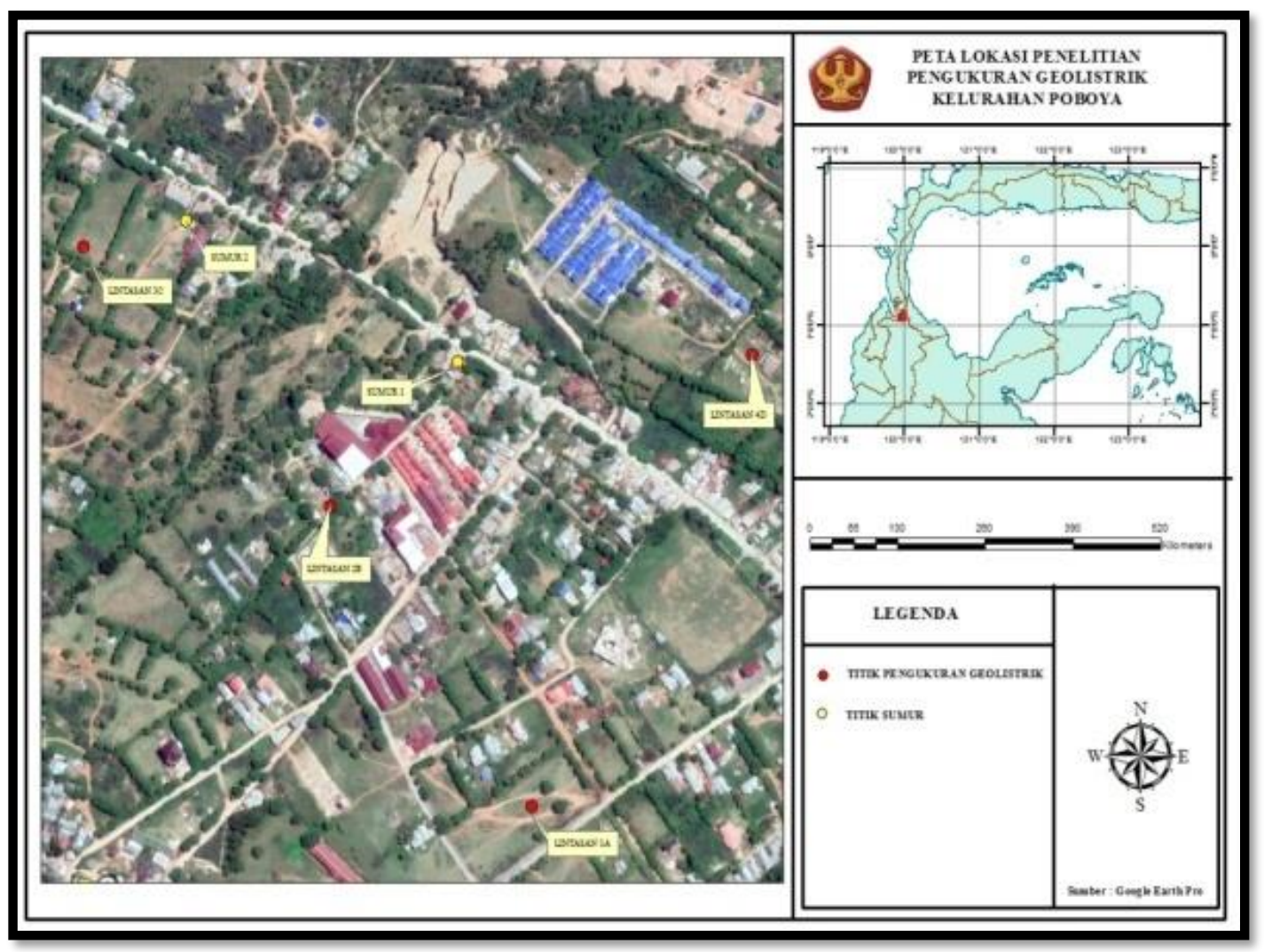

Gambar 2. Peta lokasi penelitian 
kuran membentang dari Utara ke Selatan dan penampang ini membentang dari arah Tenggara ke Bara laut. Pada penampang ini diperoleh 5 lapisan, lapisan pertama diperoleh lapisan penutup atau lapisan permukaan dengan nilai resistivitas berkisar 82,95-822,87 $\Omega \mathrm{m}$, lapisan kedua diperoleh lapisan lempung dengan nilai resistivitas berkisar 19,48-24,81 $\Omega \mathrm{m}$, lapisan ketiga diperoleh lapisan batuan keras dengan nilai resistivitas berkisar 212,55-807,71 $\Omega \mathrm{m}$, lapisan keempat diperoleh lapisan lempung dengan nilai resistivitas berkisar 20,92-26,33 $\Omega \mathrm{m}$, lapisan kelima diperoleh lapisan pasir, krikil, dan batu pasir dengan nilai resistivitas berkisar 34,52-69,92 $\Omega \mathrm{m}$.

Dari penampang ini ditemukan adanya lapisan akuifer yang divisualisasikan dengan warna kuning, lapisan ini diduga terdiri dari pasir, kerikil, dan batu pasir yang bersifat permeabel dengan kedalaman yg berkisar 84,07-86,03 m bmt. Lapisan ini makin tipis mengikuti topografi. Disekitar penampang terdapat 2 sumur bor, sumur pertama berada di Titik ukur $\mathrm{L}_{2}$ dengan jarak $171 \mathrm{~m}$ dari titik pengukuran dengan kedalaman $\pm 75 \mathrm{~m}$ dan sumur kedua berada pada Titik ukur $\mathrm{L}_{3}$ dengan jarak $96 \mathrm{~m}$ dari titik pengukuran dengan kualitas air jernih. Nilai daya hantar listrik (DHL) pada sumur pertama sebesar $665 \mu \mathrm{S} / \mathrm{cm}$ dan sumur kedua $770 \mu \mathrm{S} / \mathrm{cm}$. Kondisi diatas permukaan tanah sangat kering.

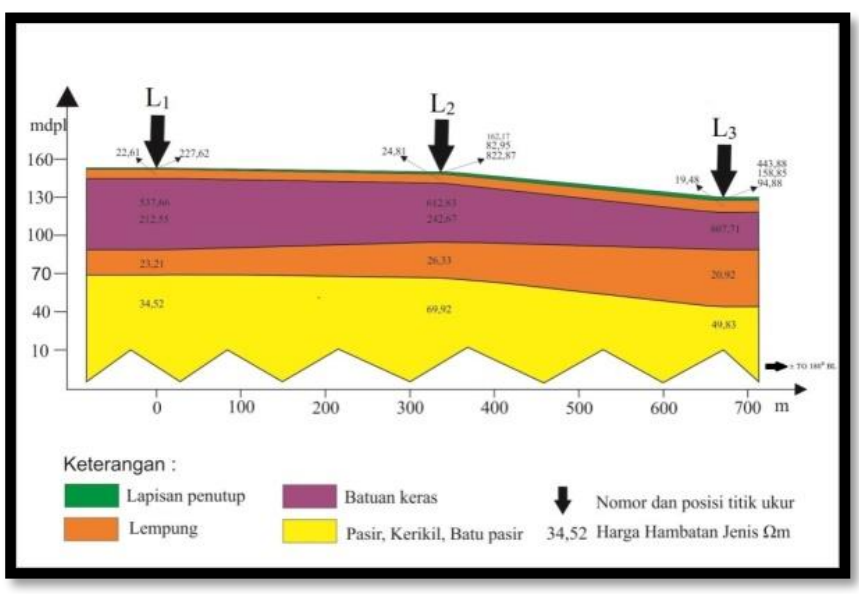

Gambar 3. Penampang hambatan jenis model A-C

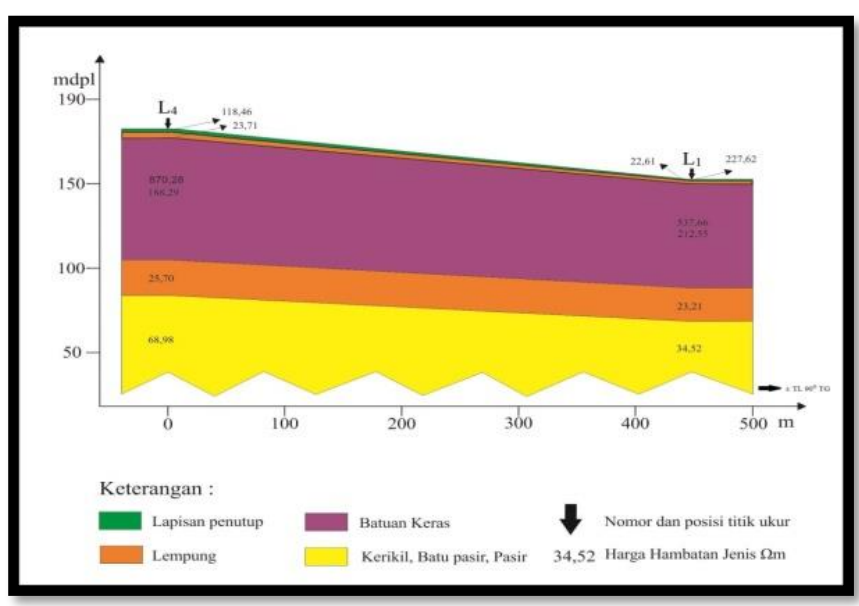

Gambar 4. Penampang hambatan jenis model D-A

Penampang hambatan jenis model D-A pada Gambar 4 menunjukkan korelasi antara 2 titik pengukuran yaitu $\mathrm{L}_{4}$ dan $\mathrm{L}_{1}$. Jarak $\mathrm{L}_{4}$ ke $\mathrm{L}_{1}$ yang terukur sebesar $448 \mathrm{~m}$ dengan ketinggian yang terukur 153 -183 mdpl. Di penampang ini, setiap titik pengukuran arah bentangannya berbeda-beda untuk $\mathrm{L}_{4}$ arah bentangannya dari timur kebarat dan $\mathrm{L}_{1}$ arah bentangan dari utara keselatan dan penampang ini membentang dari arah Timur laut ke Tenggara. Pada penampang ini diperoleh 5 lapisan untuk lapisan pertama diperoleh lapisan penutup atau lapisan permukaan dengan nilai resistivitas berkisar 118,46$227,62 \Omega \mathrm{m}$, lapisan kedua diperoleh lapisan lempung dengan nilai resistivitas berkisar 22,61-23,71 $\Omega \mathrm{m}$, lapisan ketiga diperoleh lapisan batuan keras dengan nilai resistivitas berkisar 188,229-870,28 $\Omega \mathrm{m}$, lapisan keempat diperoleh lapisan lempung dengan nilai resistivitas berkisar 23,21-25,70 $\Omega \mathrm{m}$, lapisan kelima diperoleh lapisan pasir, krkil, dan batu pasir dengan nilai resistivitas berkisar 34,52-68,98 $\Omega \mathrm{m}$. Dari penampang ini ditemukan adanya lapisan akuifer yang divisualisasikan dengan warna kuning, lapisan ini diduga terdiri dari pasir, kerikil, dan batu pasir yang bersifat permeabel. Dengan kedalaman yg berkisar 84,07 sampai dengan kedalaman lebih dari 98,80 m bmt. Lapisan ini makin tipis mengikuti topografi. Kondisi diatas permukaan tanah sangat kering. Disekitar penampang ini tidak ditemukan adanya sumur warga.

Nilai resistivitas pada penelitian yang pernah dilakukan oleh Puspitasari (2020), untuk mendeteksi lapisan akuifer di Desa Pombewe Kabupaten Sigi memiliki nilai resistivitas yang diperoleh berkisar 45,70-56,46 $\Omega \mathrm{m}$ dengan kedalaman berkisar 70,68-144,93 m bmt. Dengan demikian dapat disimpulkan bahwa nilai pengukuran yang diperoleh telah mendekati penelitian sebelumnya dengan nilai resistivitas berkisar 28-70 $\Omega \mathrm{m}$ hingga kedalaman berkisar 83,48-98,80 m bmt.

\section{KESIMPULAN}

Berdasarkan hasil dan tujuan penelitian dapat disimpulkan bahwa Nilai resistivitas lapisan akuifer di Kelurahan Poboya Kecamatan Mantikulore Kota Palu berkisar 34,52-69,92 $\Omega \mathrm{m}$ dengan kedalaman berkisar 83,48 sampai dengan kedalaman lebih dari 98,80 m bmt. Diduga lapisan tersebut terdiri dari pasir, kerikil dan batu pasir yang bersifat permeabel dan dapat diperkirakan daerah yang berpotensi mempunyai air tanah dilihat dari kedalaman lapisan akuifer yang berkisar 83,48 sampai dengan kedalaman lebih dari 98,80 m bmt. Lapisan ini menyebar dari arah utara ke arah selatan dan dari arah timur ke arah barat. Umumnya lapisan ini berada di bawah lapisan lempung yang sifatnya impermeabel.

\section{REFERENSI}

[1] Sultan. (2009). Penyelidikan Geolistrik Resistivity Pada Penentun Titik Sumur Bor untuk Pengairan di Daerah Garongkong Desa Lempang Kecamatan Tenete Rianja Barru. Skripsi. Teknik Universitas Hasanuddin, Makassar.

[2] Halik, Gusfan. (2008). Pendugaan Potensi Airtanah dengan Metode Geolistrik Konfigurasi Schlumberger di Kampus Tegal Boto Universitas Jember. Jurnal Penelitian, 8(2), 109 - 114.

[3] Hanifa, Dinisa. (2016). Penentuan lapisan akuifer airtanah dengan metode geolistrik konfigurasi schlumberger. Jurna Fisika FLUX, 13(1), 30 - 39.

[4] Suharyadi, (1984). Geohidrologi. Yogyakarta: Kanisius.

[5] Ray, L.K.J.R., M.A. Kohler \& J.L.H. Paulus, (1989). Hidrologi untuk Insinyur, 3ed. Bandung: Erlangga.

[6] Unib, M., dkk, (2006). Aquifer dan Pola Aliran Air Tanah. Bandung: Pusat Lingkungan Geologi. 
[7] Taib, M.I.T., (1990). Diktat Kuliah Eksplorasi Geolistrik. Departemen Teknik Geofisika. Bandung: Institut Teknologi Bandung.

[8] Telford, W.M., L.P. Geldart, R.E. Sheriff \& D.A. Keys, (1998). Applied Geophysics. Edisi 1. Cambridge University Press. Cambridge.
[9] Loke, M.H, (2000). Electrical Imaging Surveys for Enviromental and Engineering Studies: A Partical Guide to 2-D and 3-D Surveys. 